\title{
AMPLIFIED LUMINESCENCE AND GENERATION DYNAMICS OF THE DIODE PUMPED ERBIUM-YTTERBIUM LASER
}

\author{
M.V. Bogdanovich ${ }^{\text {a }}$, G.I. Ryabtsev ${ }^{\text {a }}$, A.I. Yenzhyieuski ${ }^{a}$, L.I. Burov ${ }^{\mathrm{b}}$, \\ A.G. Ryabtsev ${ }^{\text {b }}$, M.A. Shchemelev ${ }^{\text {b }}$, and A.S. Smal ${ }^{\mathrm{c}}$ \\ ${ }^{a}$ B.I. Stepanov Institute of Physics, National Academy of Sciences of Belarus, Nezalezhnasti Ave 68, 220072 Minsk, Belarus \\ E-mail: ryabtsev@dragon.bas-net.by \\ ${ }^{\mathrm{b}}$ Belarusian State University, Nezalezhnasti Ave 4, 220050 Minsk, Belarus \\ ${ }^{\mathrm{c}}$ Brest State Technical University, Moskovskaya 267, 224017 Brest, Belarus
}

Received 13 June 2007; revised 28 September 2007; accepted 21 November 2007

\begin{abstract}
The influence of the cavity trapped amplified luminescence (CTAL) on the threshold, power and dynamic characteristics of $\mathrm{Er}, \mathrm{Yb}$ : glass lasers with end and side diode pump configurations has been studied. The CTAL loss coefficient has been evaluated using the luminescence balance equation. The inverse proportion dependence of the CTAL loss coefficient on the cavity length has been revealed. It has been shown that amplification of luminescence in the laser cavity leads to a significant increase of the threshold pump power ( $\sim 3-5$ times). The $\mathrm{Er}, \mathrm{Yb}$ : glass laser generation dynamics has been modelled taking into account the luminescence evolution beginning with the onset of the diode pumping pulse. Depending on the diode pumping pulse amplitude, the increase or decrease of the Er, $\mathrm{Yb}$ : glass laser pulse generation delay can be observed.
\end{abstract}

Keywords: amplified luminescence, Er, $\mathrm{Yb}$ : glass laser, diode pumping

PACS: 42.55.Xi, 42.60.Mi

\section{Introduction}

Diode pumped Er, $\mathrm{Yb}$ : glass lasers emitting within the eye-safe spectral region $(1.5-1.6 \mu \mathrm{m})$ are widely used in many applications [1-3]. Spectroscopic (stimulated emission cross-section, upper laser level lifetime, etc.), as well as lasing (output beam quality, lasing spectra, etc.) characteristics of different $\mathrm{Er}, \mathrm{Yb}$ : glass active media are investigated intensively [4-6]. However, there are only a few papers devoted to the $\mathrm{Er}, \mathrm{Yb}$ : glass laser emission dynamics [5,7]. Unfortunately, the experimentally observed complicated form of the $\mathrm{Er}, \mathrm{Yb}$ : glass laser emission dynamics cannot be explained by the existing theoretical models. Thus, for the correct simulation of the Er, $\mathrm{Yb}$ : glass laser dynamics the additional processes such as amplification of luminescence, optical transitions in different optical centres, up-conversion and cross-relaxation should be involved in the consideration.

The effect of amplified luminescence on the threshold, output power, and dynamics of semiconductor lasers is widely studied [8-10]. For this type of lasers it has been shown that the increase of the threshold current density, decrease of the lasing output power, as well as the remarkable change of transient characteristics can be induced by the cavity trapped amplified luminescence (CTAL). There is a variety of papers devoted to the methods of the CTAL suppression in solid state lasers of various configurations and development of solid state light sources emitting in the luminescence amplification mode [11-13]. However, the influence of amplified luminescence on the threshold, power, and dynamic characteristics of solid state lasers is studied insufficiently.

In this work the dynamics and output characteristics of Er, $\mathrm{Yb}$ : glass lasers are simulated. The main attention is paid to the investigation of the CTAL effect on the laser operational parameters. Side and end diode pump configurations are considered.

\section{Theoretical model}

The developed approach is based on the self-consistent rate equation set for population densities of erbium $N_{\mathrm{Er}}$ and ytterbium $N_{\mathrm{Yb}}$ ions and the number of emitted photons. The number of luminescence $q_{\text {lum }}$ and $q_{\text {las }}$ lasing photons is considered. Processes of radiation absorption and emission as well as the excitation 

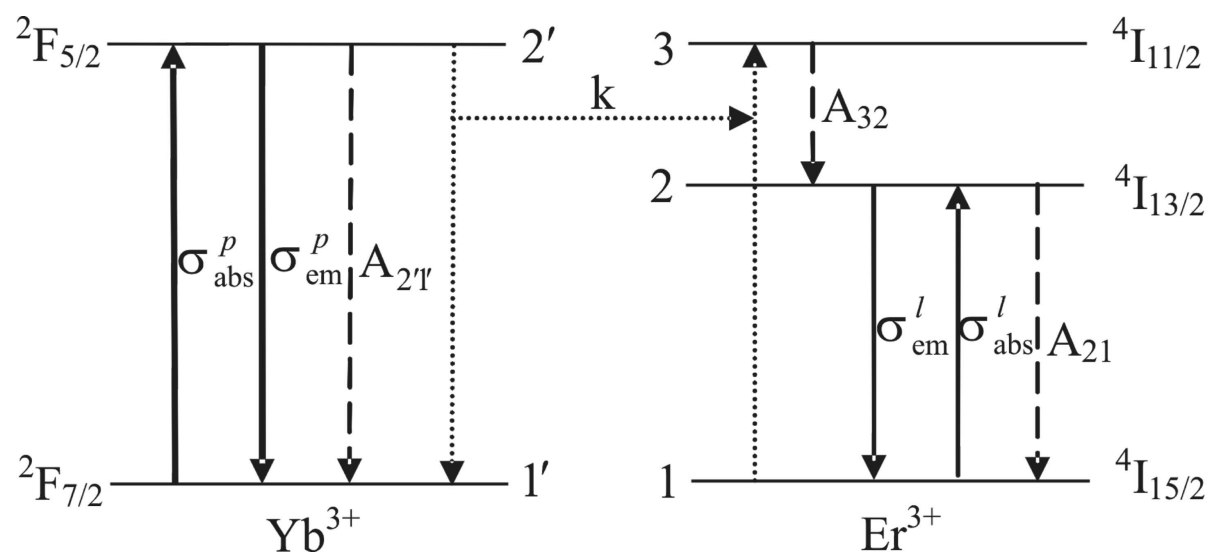

Fig. 1. Energy level diagram for the $\mathrm{Er}^{3+}-\mathrm{Yb}^{3+}$ laser active element.

energy transfer and spontaneous emission amplification are taken into account in the proposed model.

The energy level diagram for the erbium-ytterbium laser active element together with essential radiative and non-radiative transitions is presented in Fig. 1. As a consequence of diode pump radiation absorption, the $\mathrm{Yb}^{3+}$ ions are excited from the ${ }^{2} \mathrm{~F}_{7 / 2}$ level to the ${ }^{2} \mathrm{~F}_{5 / 2}$ energy level. The excitation energy of the $\mathrm{Yb}^{3+}$ ion is transferred in a non-radiative manner to the $\mathrm{Er}^{3+}$ ion through the ${ }^{4} \mathrm{I}_{15 / 2} \rightarrow{ }^{4} \mathrm{I}_{11 / 2}$ transition. The excited $\mathrm{Er}^{3+}$ ions relax quickly to the metastable energy level ${ }^{4} \mathrm{I}_{13 / 2}$, and lasing occurs in the channel ${ }^{4} \mathrm{I}_{13 / 2} \rightarrow{ }^{4} \mathrm{I}_{15 / 2}$.

The developed rate equation set for the Er, $\mathrm{Yb}$ : glass laser under consideration can be written as [7,11]:

$$
\left\{\begin{aligned}
\frac{\mathrm{d} N_{2^{\prime}}}{\mathrm{d} t} & =\sigma_{\mathrm{abs}}^{\mathrm{p}}\left(N_{1^{\prime}}-N_{2^{\prime}}\right) \Phi_{\mathrm{p}}-A_{2^{\prime} 1^{\prime}} N_{2^{\prime}} \\
& -k N_{2^{\prime}} N_{1}, \\
\frac{\mathrm{d} N_{1}}{\mathrm{~d} t} & =\left(\sigma_{\mathrm{em}}^{\mathrm{las}} N_{2}-\sigma_{\mathrm{abs}}^{\mathrm{las}} N_{1}\right)\left(\Phi_{\mathrm{las}}+\Phi_{\mathrm{lum}}\right) \\
& +A_{21} N_{2}-k N_{2^{\prime}} N_{1}, \\
\frac{\mathrm{d} N_{2}}{\mathrm{~d} t} & =-\left(\sigma_{\mathrm{em}}^{\mathrm{las}} N_{2}-\sigma_{\mathrm{abs}}^{\mathrm{las}} N_{1}\right)\left(\Phi_{\mathrm{las}}+\Phi_{\mathrm{lum}}\right) \\
& -A_{21} N_{2}+A_{32} N_{3}, \\
\frac{\mathrm{d} q_{\mathrm{las}}}{\mathrm{d} t} & =\frac{c}{n}\left[\left(\sigma_{\mathrm{em}}^{\mathrm{las}} N_{2}-\sigma_{\mathrm{abs}}^{\text {las }} N_{1}\right)-k^{\text {las }}\right] q_{\mathrm{las}} \\
& +\delta_{\mathrm{las}} A_{21} N_{2} l S, \\
\frac{\mathrm{d} q_{\mathrm{lum}}}{\mathrm{d} t} & =\frac{c}{n}\left[\left(\sigma_{\mathrm{em}}^{\text {las }} N_{2}-\sigma_{\mathrm{abs}}^{\text {las }} N_{1}\right)-k^{\text {lum }}\right] q_{\mathrm{lum}} \\
& +\delta_{\mathrm{lum}} A_{21} N_{2} l S,
\end{aligned}\right.
$$

where $N_{1^{\prime}}, N_{2^{\prime}}$ are the $\mathrm{Yb}^{3+}$ population densities for
${ }^{2} \mathrm{~F}_{7 / 2}$ and ${ }^{2} \mathrm{~F}_{5 / 2}$ energy levels, respectively; $N_{1}, N_{2}$, $N_{3}$ are the $\mathrm{Er}^{3+}$ population densities for ${ }^{4} \mathrm{I}_{15 / 2},{ }^{4} \mathrm{I}_{13 / 2}$, and ${ }^{4} \mathrm{I}_{11 / 2}$ energy levels, respectively; $\sigma_{\text {abs }}^{\mathrm{p}}$ is the absorption cross-section at the diode pump wavelength (emission cross-section $\sigma_{\mathrm{em}}^{\mathrm{p}}$ given in Fig. 1 is supposed to be equal to $\left.\sigma_{\text {abs }}^{\mathrm{p}}\right) ; \sigma_{\mathrm{abs}}^{\text {las }}, \sigma_{\mathrm{em}}^{\text {las }}$ are the absorption and emission cross-sections at the lasing wavelength, respectively; $A_{2^{\prime} 1^{\prime}}$ is the de-excitation rate related to transitions from the $\mathrm{Yb}^{3+}$ excited state to the ytterbium ground state; $A_{21}$ is the de-excitation rate related to transitions from the $\mathrm{Er}^{3+}{ }^{4} \mathrm{I}_{13 / 2}$ state to the erbium ground state; $A_{32}$ is the de-excitation rate related to transitions from the $\mathrm{Er}^{3+}{ }^{4} \mathrm{I}_{11 / 2}$ state to the ${ }^{4} \mathrm{I}_{13 / 2}$ state; $\Phi_{\mathrm{p}}, \Phi_{\text {las }}$, and $\Phi_{\text {lum }}$ are the pump, lasing, and amplified luminescence photon fluxes, respectively; $k$ is the coefficient of the energy transfer from the $\mathrm{Yb}^{3+}{ }^{2} \mathrm{~F}_{5 / 2}$ level to the $\mathrm{Er}^{3+}{ }^{4} \mathrm{I}_{11 / 2}$ level; $\delta_{\text {las }}, \delta_{\text {lum }}$ are the spontaneous emission factors for lasing and amplified luminescence, respectively; $k^{\text {las }}$ and $k^{\text {lum }}$ are the cavity loss coefficients for lasing and amplified luminescence, respectively; $c$ is the light velocity, and $n$ is the active medium refractive index.

The first three equations of set (1) describe the evolution of population densities in ytterbium and erbium ions. This group of equations is formulated under the condition that all rare earth ions are distributed over the energy levels stated in Fig. 1:

$$
N_{1^{\prime}}+N_{2^{\prime}}=N_{\mathrm{Yb}}, N_{1}+N_{2}+N_{3}=N_{\mathrm{Er}},
$$

where $N_{\mathrm{Yb}}$ is the $\mathrm{Yb}^{3+}$ ion density and $N_{\mathrm{Er}}$ is the $\mathrm{Er}^{3+}$ ion density. Since it has been shown that the up-conversion, cross-relaxation, excited state absorption, and energy back transfer from $\mathrm{Er}^{3+}$ to $\mathrm{Yb}^{3+}$ ions insignificantly influence the dynamics of the $\mathrm{Er}, \mathrm{Yb}$ : glass laser [7], these processes are neglected in the present approach. 
In the case of the uniform distribution the photon fluxes $\Phi_{\mathrm{p}}, \Phi_{\text {las }}$, and $\Phi_{\text {lum }}$ can be expressed in the following way:

$$
\begin{gathered}
\Phi_{\mathrm{p}}=\frac{P_{\mathrm{abs}}}{h \nu_{\mathrm{p}} S_{\mathrm{m}}}, \\
\Phi_{\text {las }}=\frac{c q_{\mathrm{las}}}{n l S_{\mathrm{m}}}, \\
\Phi_{\text {lum }}=\frac{c q_{\mathrm{lum}}}{n l S_{\mathrm{m}}},
\end{gathered}
$$

where $P_{\text {abs }}$ is the absorbed radiation pump power; $h \nu_{\mathrm{p}}$ is the pump radiation photon energy; $S_{\mathrm{m}}$ is the mode cross-section area, and $l$ is the cavity length.

The second group of rate equation set (1) includes $q_{\text {las }}, q_{\text {lum }}$ time derivatives and simulates joint dynamics of amplified luminescence as well as lasing photons within the laser cavity. Evolution conditions are different for CTAL and lasing fluxes. In contrast to the lasing radiation flux, the CTAL flux is characterized by a larger propagation spatial angle and larger contribution of spontaneous emission $[8,14]$. This fact can be taken into account by introduction of two rate equations for CTAL and lasing photons with different cavity loss coefficients and spontaneous emission factors [9].

The spontaneous emission factor for lasing $\delta_{\text {las }}$ was set equal to $10^{-3}$ by analogy with the factor for the semiconductor laser [15]. The factor $\delta_{\text {lum }}$ was defined in accordance with the following expression [14]:

$$
\delta_{\operatorname{lum}}=\frac{(n-1)(n+3)}{(n+1)^{2}} .
$$

For the investigated $\mathrm{Er}, \mathrm{Yb}:$ glass laser the value $\delta_{\text {lum }}=0.38$.

The cavity loss coefficient for lasing radiation was defined as

$$
k^{\text {las }}=-\frac{\ln \left[R_{1} R_{2}(1-\rho)\right]}{2 l},
$$

where $R_{1}$ and $R_{2}$ are the reflection coefficients of the cavity mirrors, and $\rho$ is the internal losses per round trip.

CTAL losses can be characterized by the coefficient $k^{\text {lum }}$ averaged over the cavity volume and over all directions of CTAL propagation. The CTAL loss coefficient evaluation techniques are well-defined for semiconductor lasers [16, 17]. However, no techniques were developed for determination of the CTAL loss coefficient values for solid-state lasers.

The method of evaluation of the $k^{\text {lum }}$ coefficient developed in our work for the $\mathrm{Er}, \mathrm{Yb}$ : glass lasers is based on the luminescence balance equation written in the steady-state approach:

$$
A_{21} h \nu_{21} N_{2}+\left(\sigma_{\mathrm{em}}^{\mathrm{las}} N_{2}-\sigma_{\text {abs }}^{\text {las }} N_{1}\right) S_{\text {lum }}=k^{\text {lum }} S_{\text {lum }},
$$

where $h \nu_{21}$ is the energy of the photon emitted due to the $\mathrm{Er}^{3+}$ ion transition ${ }^{4} \mathrm{I}_{13 / 2} \rightarrow{ }^{4} \mathrm{I}_{15 / 2}$, and $S_{\text {lum }}$ is the luminescence flux density. Under steady-state conditions the luminescence increment must be compensated by the losses of luminescence. This relation holds at the laser threshold and below. To calculate the $k^{\text {lum }}$ coefficient from Eq. (6), it is necessary to define $N_{1}, N_{2}$, and $S_{\text {lum }}$ steady-state values at a selected pump level. Steady-state values of $S_{\text {lum }}$ in the case when the laser cavity length is significantly larger than the laser mode diameter can be determined on the basis of the following one-dimensional transfer equation [14]:

$$
\left\{\begin{aligned}
\pm \frac{\mathrm{d} S_{\text {lum }}^{ \pm}(x)}{\mathrm{d}(b x)}= & -\left(\sigma_{\text {em }}^{\text {las }} N_{2}-\sigma_{\text {abs }}^{\text {las }} N_{1}\right) S_{\text {lum }}^{ \pm}(x) \\
& +\delta_{\text {lum }} A_{21} h \nu_{21} N_{2}, \\
S_{\text {lum }}^{+}(0)= & R_{1} S_{\text {lum }}^{-}(0), \\
S_{\text {lum }}^{-}(l)= & R_{2} S_{\text {lum }}^{+}(l),
\end{aligned}\right.
$$

where $S_{\text {lum }}^{+}$and $S_{\text {lum }}^{-}$are the CTAL flux densities propagating along the laser resonator $O x$ axis in the opposite directions, and $b$ is the factor representing the increase of the mean path due to CTAL propagation at different angles $(b>1)$. The factor $b$ can be estimated using the expression [14]

$$
b \geq \frac{2 n}{1+n} .
$$

The population densities $N_{1}$ and $N_{2}$ are the functions of the CTAL flux density. To take into account these dependences it is proposed to solve the first group of rate equation set (1) devoted to the evolution of population densities of $\mathrm{Yb}^{3+}$ and $\mathrm{Er}^{3+}$ ions at stationary approximation. It should be noted that the lasing photon flux $\Phi_{\text {las }}$ is not included in the present equation group because $\Phi_{\text {las }}$ is negligibly small in comparison with $\Phi_{\text {lum }}$ at the laser threshold and below. The functions $N_{1}\left(S_{\text {lum }}\right)$ and $N_{2}\left(S_{\text {lum }}\right)$ obtained from stationary rate equation set (1) are introduced in Eq. (7) and then used in the iterative procedure.

Transfer Eq. (7) can be numerically solved using the 4th-order Runge-Kutta method. The CTAL flux density distributions over the cavity length $S_{\text {lum }}(x)$ obtained for two near threshold pump power values are presented in Fig. 2. It is important that according to 


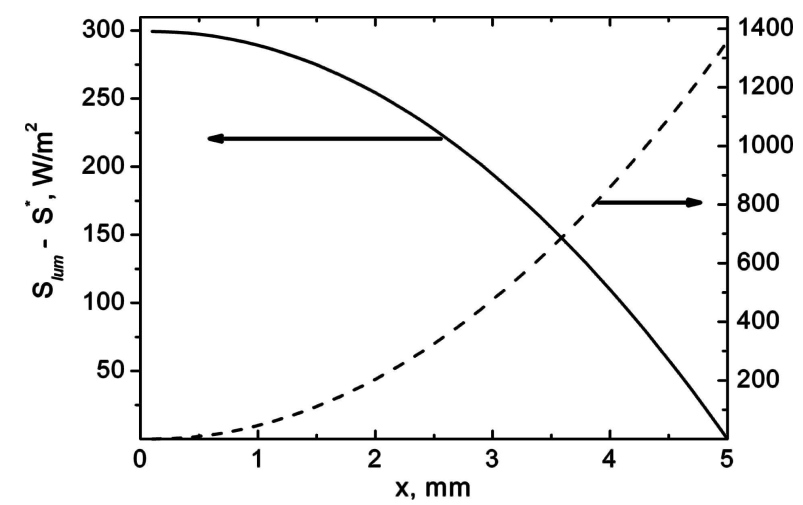

Fig. 2. Cavity trapped amplified luminescence flux density $S_{\text {lum }}$ distribution within the laser rod (along the resonator axis $O x$ ) at 20.4 (solid) and $23.0 \mathrm{~mW}$ (dashed) pump power for $l=5 \mathrm{~mm}$. For convenience the CTAL flux density is presented in the form of the difference $S_{\text {lum }}(x)-S^{*}$, where the $S^{*}$ parameter is equal to $9.7 \cdot 10^{7}$ and $1.1 \cdot 10^{8} \mathrm{~W} / \mathrm{m}^{2}$ for the 20.4 and $23.0 \mathrm{~mW}$ pump power levels, respectively.

[18] the convex form of the $S_{\text {lum }}(x)$ distribution (solid curve) corresponds to the pump level below the laser threshold while the concave form of $S_{\text {lum }}(x)$ (dashed curve) relates to the above threshold conditions, for the threshold pump power the uniform $S_{\text {lum }}(x)$ distribution must be achieved. Consequently, according to the conditions of Eq. (6) validity only the concave form or quasi uniform $S_{\text {lum }}(x)$ curves must be applied. The mean value of the near threshold $S_{\text {lum }}(x)$ distribution can be used for $k^{\text {lum }}$ evaluation because of slight variations of the CTAL flux density along the cavity $(\sim 0.001 \%)$.

The mean value of $S_{\text {lum }}(x)$ denoted as the term $S_{\text {lum }}$ and corresponding magnitudes $N_{1}$ and $N_{2}$ are used in Eq. (6) to determine the CTAL loss coefficient $k^{\text {lum }}$. The results of the performed calculations show that the $k^{\text {lum }}$ value is relatively weak depending on the diode pump radiation power $P_{\text {pump }}$. The CTAL loss coefficient can be considered as a constant at different diode pump power levels for the given laser within the accuracy limits of $10 \%$.

In the present work the erbium-ytterbium glass laser generation dynamics is modelled on the basis of rate equation set (1) taking into account the effect of CTAL. Time evolution of the CTAL photon number is simulated using the CTAL spontaneous emission factor $\delta_{\text {lum }}$ and the CTAL loss coefficient $k^{\text {lum }}$. The value of $k^{\text {lum }}$ is estimated at the laser threshold in accordance with the above-mentioned technique.

\section{Results and discussion}

Active medium of the investigated diode pumped solid-state laser was regarded as a cylindrical rod made of phosphate glass co-activated by $\mathrm{Er}^{3+}$ and $\mathrm{Yb}^{3+}$ ions. Reflection coefficients of the rod facets $R_{1}$ and $R_{2}$ were supposed to be equal to 97 and $100 \%$. The concentrations of erbium and ytterbium ions were $5 \cdot 10^{25}$ and $4 \cdot 10^{27} \mathrm{~m}^{-3}$, respectively. The Er, $\mathrm{Yb}$ : phosphate glass parameters are listed in Table 1.

End and side diode pump configurations were analysed. The type of the diode pump configurations was specified by selection of the lasing mode diameter $d_{\mathrm{m}}$ and the active medium length. For the end diode pump configuration, the $d_{\mathrm{m}}$ value was taken to be equal to $100 \mu \mathrm{m}$ and $l$ was chosen in the range of $2-5 \mathrm{~mm}$ while for the side pump $d_{\mathrm{m}}=3 \mathrm{~mm}$ and $l=10-20 \mathrm{~mm}$. The absorbed pump power in case of the end diode pump geometry can be calculated on the basis of the following relation:

$$
P_{\text {abs }}=P_{\text {pump }} \frac{1-\mathrm{e}^{-\alpha l}}{\alpha l},
$$

where $\alpha$ is the absorption coefficient of the $\mathrm{Er}, \mathrm{Yb}$ : glass at the pump radiation wavelength. In case of the side pump configuration the relation of such type is more complicated, and for simplicity the calculations were performed in terms of $P_{\text {abs }}$. The uniform distribution of $P_{\text {abs }}$ over the cavity was supposed.

The amplified luminescence loss coefficient $k^{\text {lum }}$ values were estimated for two above-mentioned diode pumping configurations. The calculations were performed for different laser cavity lengths up to $20 \mathrm{~mm}$ using Eqs. (6), (7). The obtained values $k^{\text {lum }}$ for different cavity lengths of the end diode pumped $\mathrm{Er}, \mathrm{Yb}$ : glass laser resonator are presented in Fig. 3. The dependence $k^{\operatorname{lum}}(l)$ can be approximated with sufficiently high precision by the following function:

$$
k^{\operatorname{lum}}(l)=\frac{\Delta}{l},
$$

where $\Delta$ is the proportionality coefficient. The same inverse proportion function $k^{\operatorname{lum}}(l)$ was obtained for the side diode pumped $\mathrm{Er}, \mathrm{Yb}$ : glass laser. Consequently, the influence of the CTAL radiation on the $\mathrm{Er}, \mathrm{Yb}$ : glass laser generation dynamics can be quite easily taken into account for different cavity lengths.

In order to reveal the role of CTAL in the dynamics and output characteristics of the Er, Yb : glass laser, modelling was performed taking and not taking into consideration the CTAL flux. The dependences of the end diode pumped glass laser output power on the 
Table 1. Er, Yb : glass parameters.

\begin{tabular}{|c|c|c|c|c|c|c|c|}
\hline$A_{21}, \mathrm{~s}^{-1}$ & $A_{32}, \mathrm{~s}^{-1}$ & $A_{2^{\prime} 1^{\prime}}, \mathrm{s}^{-1}$ & $k, \mathrm{~m}^{3} \mathrm{~s}^{-1}$ & $n$ & $\sigma_{\mathrm{abs}}^{\mathrm{las}}, \mathrm{m}^{2}$ & $\sigma_{\mathrm{em}}^{\text {las }}, \mathrm{m}^{2}$ & $\alpha, \mathrm{m}^{-1}$ \\
\hline \multicolumn{5}{|c|}{ [7] } & \multicolumn{3}{|c|}{ Measured } \\
\hline 113.6 & $10^{5}$ & $10^{3}$ & $7.1 \cdot 10^{-21}$ & 1.55 & $5.17 \cdot 10^{-25}$ & $6.20 \cdot 10^{-25}$ & 2500 \\
\hline
\end{tabular}

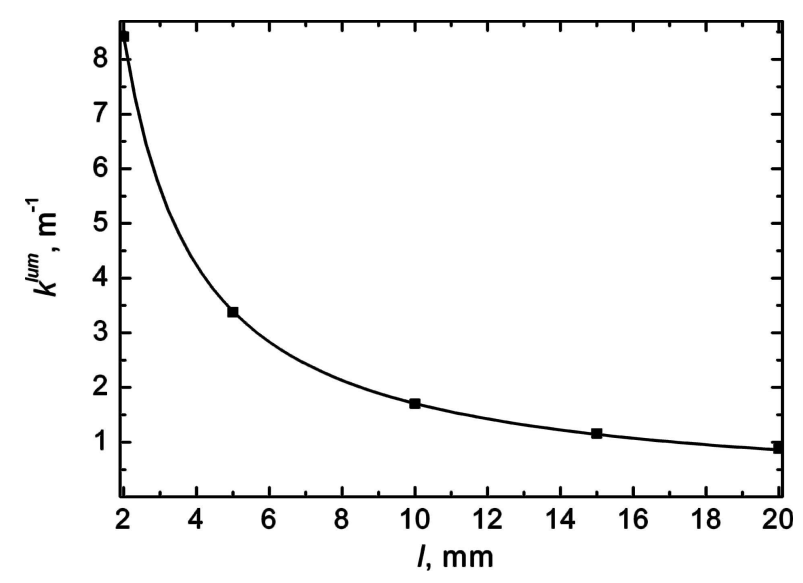

Fig. 3. Amplified luminescence optical loss coefficient $k^{\text {lum }}$ evaluated as a function of the laser active element length $l$ for the end diode pump configuration.

pump power for both considered cases are shown in the inset of Fig. 4. As can be seen the presence of amplified luminescence leads to the threshold pump power $P_{\text {th }}$ increase from approximately 23 to $105 \mathrm{~mW}$. The laser slope efficiencies obtained in both cases are virtually equal. Thus, the CTAL photon number under the steady-state conditions is almost independent of the pump power level.

The evolution of the number of lasing (curves 1,2 ) and amplified luminescence (curve 3) photons within the end diode pumped $\mathrm{Er}, \mathrm{Yb}$ : glass laser cavity $(l=$ $5 \mathrm{~mm}$ ) at two different pump power values is presented in Fig. 4(a,b). Dynamics of the number of lasing photons $q_{\text {las }}$ was simulated not taking (curve 1 ) and taking into account (curve 2) CTAL. As shown in Fig. 4(a) the CTAL gives rise to a variation of the laser turn-on delay and decrease of the $q_{\text {las }}(t)$ oscillation frequency, oscillation decay time, and the $q_{\text {las }}$ steady-state value. The effect of CTAL is larger for the near threshold pump power level. For example, at the diode pump power of $150 \mathrm{~mW}\left(P_{\text {pump }} / P_{\text {th }} \sim 1.5\right)$ the steady-state value of $q_{\text {las }}$ is decreased by the factor larger than 2.5 due to the CTAL influence. On the other hand, at $P_{\text {pump }}=$ $600 \mathrm{~mW}\left(P_{\text {pump }} / P_{\text {th }} \sim 6\right)$ the lasing photon number stationary value is reduced only by $15 \%$ when CTAL is taken into account.

We would like to give attention to the non-obvious fact that the difference between the laser turn-on delays $\Delta t_{\text {lum }}$ calculated taking and not taking into account

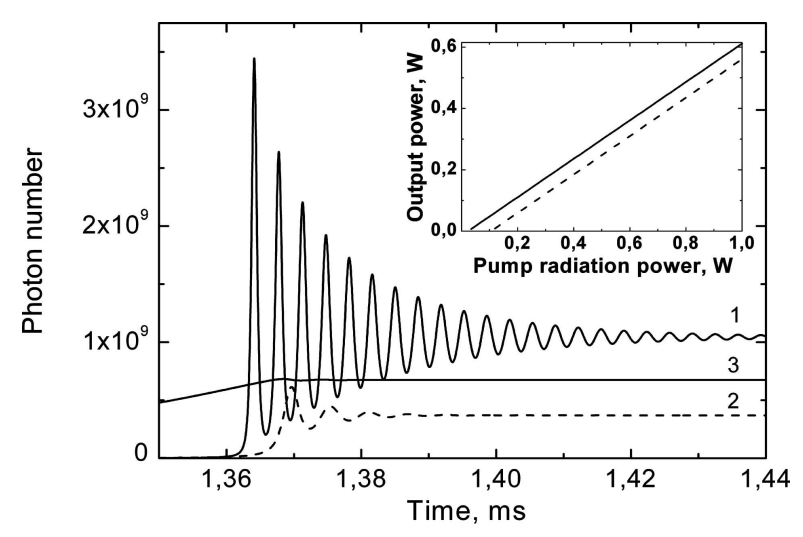

(a)

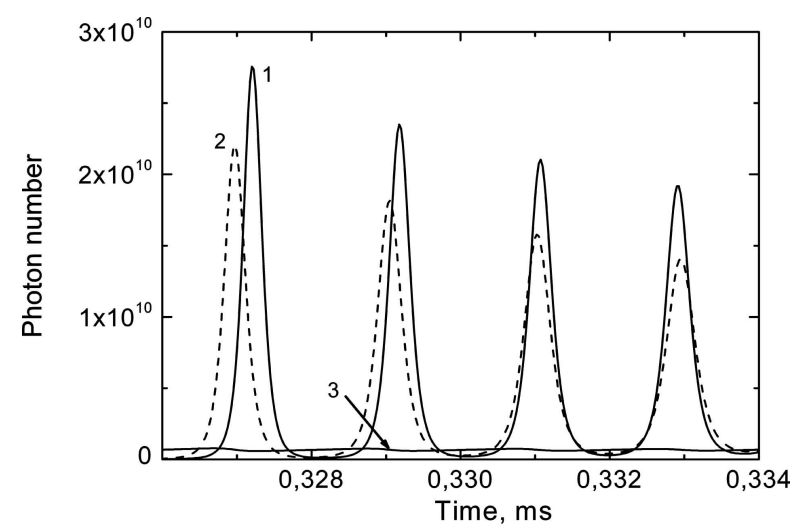

(b)

Fig. 4. Time evolution of lasing photon number not taking (1) and taking into account (2) amplified luminescence together with time evolution of CTAL photon number (3) at (a) 150 and (b) $600 \mathrm{~mW}$ pump power levels for the case of the end diode pump configuration. The laser rod length is equal to $5 \mathrm{~mm}$. The dependence of the output $\mathrm{Er}, \mathrm{Yb}$ : glass laser power on the pump radiation power for the end diode pump geometry is presented in the inset.

CTAL can be both positive and negative. As seen from Fig. 4(a), taking into account CTAL leads to a slight increase of the laser turn-on delay $\left(\Delta t_{\text {lum }}>0\right)$ at a relatively low pump power. On the contrary, the laser turn-on delay is decreased $\left(\Delta t_{\text {lum }}<0\right)$ at a relatively high pump power, see Fig. 4(b).

This phenomenon can be explained in the following way. After the pump source turning on, the spontaneous transitions ${ }^{4} \mathrm{I}_{13 / 2} \rightarrow{ }^{4} \mathrm{I}_{15 / 2}$ are initiated. A high value of the spontaneous emission factor related to amplified luminescence results in a higher growth rate of the number of the CTAL photons in comparison with $q_{\text {las. }}$. CTAL photons propagating within the active 
medium induce absorbing ${ }^{4} \mathrm{I}_{15 / 2} \rightarrow{ }^{4} \mathrm{I}_{13 / 2}$ as well as stimulated radiative ${ }^{4} \mathrm{I}_{13 / 2} \rightarrow{ }^{4} \mathrm{I}_{15 / 2}$ transitions. The absorbing transition rate dominates in comparison with the radiative transition rate until reaching the medium transparency condition $N_{2}=N_{1}=N_{\text {tr }}$. Consequently, during the period when $N_{2}<N_{\text {tr }}$, the CTAL flux serves as an additional pump source for the ${ }^{4} \mathrm{I}_{13 / 2}$ energy level. After exceeding the transparency condition, the amplified luminescence starts to behave as an additional loss source, thus leading to decrease of the ${ }^{4} \mathbf{I}_{13 / 2}$ population growth rate. As a result, the amplified luminescence contrarily affects the $N_{2}$ growth rate during time intervals when $N_{2}<N_{\text {tr }}$ and $N_{\text {tr }}<N_{2}$. Thus, the sign of the $\Delta t_{\text {lum }}$ value is defined by the relationship between the above-mentioned time intervals when $N_{0}<N_{2}<N_{\text {tr }}$ and $N_{\text {tr }}<N_{2}<N_{\text {th }}$; here $N_{0}$ is the ${ }^{4} \mathrm{I}_{13 / 2}$ initial population density corresponding to the equilibrium erbium ion distribution over the energy levels, and $N_{\mathrm{th}}$ is the lasing threshold population density of ${ }^{4} \mathrm{I}_{13 / 2}$. The relationship between the time intervals depends on the pump power and cavity losses. For example, an increase of the laser cavity length leads to a decrease of the lasing and CTAL loss coefficients. The difference between $N_{\mathrm{th}}$ and $N_{\mathrm{tr}}$ values is reduced due to the $k^{\text {las }}$ decrease while the difference between $N_{\text {tr }}$ and $N_{0}$ remains unchanged. A decrease of $k^{\text {lum }}$ results in propagation of more intensive CTAL flux within the laser cavity. As a consequence, the ${ }^{4} \mathrm{I}_{13 / 2}$ population growth rate is increased at $N_{0}<N_{2}<N_{\text {tr }}$ and decreased at $N_{\mathrm{tr}}<N_{2}<N_{\mathrm{th}}$. It has been found that the sign of $\Delta t_{\text {lum }}$ cannot be changed by the pump power variation for any cavity length. For example, the turn-on delay for the $\mathrm{Er}, \mathrm{Yb}$ : glass laser with the cavity length $(l=10 \mathrm{~mm})$ is decreased $\left(\Delta t_{\text {lum }}<0\right)$ at the threshold pump level $(\sim 250 \mathrm{~mW})$ due to the presence of the CTAL flux. At a further increase of the diode pump power the $\Delta t_{\text {lum }}$ value remains negative and tends to zero at $P_{\text {pump }} \sim 10 \mathrm{~W}$.

The peculiarities similar to those revealed in the end diode pumped $\mathrm{Er}, \mathrm{Yb}$ : glass laser generation dynamics and output characteristics are observed for the laser with the side diode pump configuration. Time evolutions of the lasing photon number and dependences of the laser output power on the absorbed pump power calculated taking (dashed) and not taking into account CTAL (solid) for the side diode pumped Er, $\mathrm{Yb}$ : glass laser $(l=10 \mathrm{~mm})$ are presented in Fig. 5. It can be seen that the influence of CTAL on the behaviour of $q_{\text {las }}(t)$ oscillation damping, the $q_{\text {las }}$ stationary value decrease, and the laser threshold increase for the side diode pump configuration is almost the same as that for the end

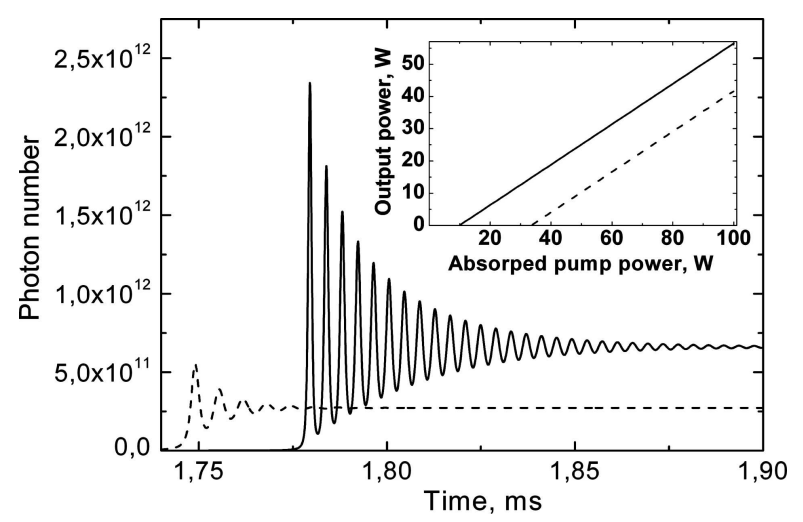

Fig. 5. Time evolution of the lasing photon number not taking (solid) and taking into account (dashed) amplified luminescence for the side diode pump configuration. The laser rod length is equal to $10 \mathrm{~mm}$. The absorbed pump power is equal to $50 \mathrm{~W}$. The dependence of the output $\mathrm{Er}, \mathrm{Yb}$ : glass laser power on the absorbed pump power for the end diode pump geometry is presented in the inset.

diode pump configuration. It should be noted that a decrease of the laser turn-on delay taking into account CTAL is more significant for the side diode pump configuration in comparison with the end pump geometry.

\section{Conclusion}

Modelling of the end and side diode pumped Er, $\mathrm{Yb}$ : glass laser dynamics and output characteristics has been performed taking into account the cavity trapped amplified luminescence. Dynamics of the number of lasing and CTAL photons has been simulated on the basis of the self-consistent rate equation set for population densities of erbium and ytterbium ions and the number of emitted photons. Lasing and CTAL photon flux evolutions have been characterized by different cavity loss coefficients and spontaneous emission factors. CTAL loss coefficient values for different $\mathrm{Er}, \mathrm{Yb}$ : glass laser cavity lengths have been determined using the luminescence balance equation. To our knowledge, the CTAL loss coefficient values and their dependences on the cavity length have been determined for the first time. It has been shown that taking into account CTAL can cause the laser turn-on delay increase or decrease depending on the laser geometry and operation conditions. The laser turn-on delay decrease related to the luminescence has been revealed because the simulation was performed starting with the equilibrium ion distribution over the energy levels.

\section{References}

[1] J.A. Hutchinson and T.H. Allik, Diode array-pumped Er, Yb : Phosphate glass laser, Appl. Phys. Lett. 60(12), 
1424-1426 (1992).

[2] Z. Mierczyk, M. Kwasny, K. Kopczynski, A. Gietka, T. Lukasiewicz, Z. Frukacz, J. Kisielewski, R. Stepien, and $\mathrm{K}$. Jedrzejewski, $\mathrm{Er}^{3+}$ and $\mathrm{Yb}^{3+}$ doped active media for 'eye safe' laser systems, J. Alloys Compounds 300-301, 398-406 (2000).

[3] A.Yu. Abazadze, V.N. Bykov, G.M. Zverev, A.A. Pleshkov, and V.A. Simakov, Highly efficient minilaser with transverse pulsed semiconductor pumping for eye-safe laser range-finding, Quantum Electron. 32(3), 210-212 (2002).

[4] B.I. Denker, B.I. Galagan, V.V. Osiko, and S.E. Sverchkov, Materials and components for miniature diode-pumped $1.5 \mu \mathrm{m}$ erbium glass laser, Laser Phys. 12(4), 697-701 (2002).

[5] G.I. Ryabtsev, T.V. Bezyazychnaya, V.V. Parastchuk, A.G. Ryabtsev, M.V. Bogdanovich, A.I. Yenzhyieuski, L.L. Teplyashin, V.V. Kuznetsova, I.P. Petrovich, A.S. Kraskovskii, and S.N. Titovez, Spectral and temporal properties of diode-pumped $\mathrm{Er}, \mathrm{Yb}$ : glass laser, Opt. Commun. 252, 301-306 (2005).

[6] G.I. Ryabtsev, M.V. Bogdanovich, A.I. Yenzhyieuski, V.V. Parastchuk, L.I. Burov, M.A. Shchemelev, A.G. Ryabtsev, V.V. Mashko, L.L. Teplyashin, and A.S. Kraskovskii, Spatial and polarization properties of the output beam of an ytterbium-erbium laser with transverse diode pumping, J. Opt. Technol. 73(5), 311314 (2006).

[7] E. Tanguy, C. Larat, and J.P. Pocholle, Modelling of the erbium-ytterbium laser, Opt. Commun. 153, 172183 (1998).

[8] L.I. Burov, I.N. Varaksa, S.V. Voitikov, M.I. Kramar, A.G. Ryabtsev, and G.I. Ryabtsev, Effect of amplified luminescence on the lasing threshold of longwavelength injection lasers, Quantum Electron. 32(3), 260-263 (2002).

[9] L.I. Burov, V.A. Savva, S.G. Rusov, A.G. Ryabtsev, G.I. Ryabtsev, A.S. Smal, and K.A. Shore, Effect of cavity trapped amplified luminescence on the dynamics of laser diodes, Nonlinear Phenom. Complex Systems 7(3), 273-282 (2004).

[10] R. Herda and O.G. Okhotnikov, Effect of amplified spontaneous emission and absorber mirror recovery time on the dynamics of mode-locked fiber lasers, Appl. Phys. Lett. 86(1), 011113-1-3 (2005).

[11] W. Koechner, Solid State Laser Engineering, 6th ed. (Springer, Berlin, 2006).

[12] A.V. Okishev, C. Dorrer, V.I. Smirnov, L.B. Glebov, and J.D. Zuegel, Spectral filtering in a diode-pumped $\mathrm{Nd}$ : YLF regenerative amplifier using a volume Bragg grating, Opt. Express 15(13), 8197-8202 (2007).

[13] I. Kelson and A.A. Hardy, Strongly pumped fiber lasers, IEEE J. Quantum Electron. 34(9), 1570-1577 (1998).

[14] A.M. Samson, Calculation of the luminescence of a finite volume with population inversion, J. Appl. Spectrosc. (USSR) 2(3), 232-242 (1965) [in Russian].

[15] K. Petermann, Calculated spontaneous emission factor for double-heterostructure injection lasers with gaininduced waveguiding, IEEE J. Quantum Electron. QE15(7), 566-570 (1979).

[16] V.P. Gribkovskii, V.K. Kononenko, G.I. Ryabtsev, and V.A. Samoilyukovich, Trapped radiation in injection lasers, IEEE J. Quantum Electron. QE-12(6), 322-326 (1976).

[17] G.I. Ryabtsev and A.S. Smal, Calculation of the loss coefficient of the amplified luminescence in the active layer of a laser diode, J. Appl. Spectrosc. 70(4), 490495 (2003).

[18] L.I. Burov, L.A. Kotomtseva, S.G. Rusov, A.G. Ryabtsev, G.I. Ryabtsev, A.S. Smal, and I.N. Waraxe, Laser diode threshold in travelling wave rate equation approach, Nonlinear Phenom. Complex Systems 5(3), 296-301 (2002). 


\title{
DIODAIS KAUPINAMO ERBIO IR ITERBIO LAZERIO SUSTIPRINTA LIUMINESCENCIJA IR GENERAVIMO DINAMIKA
}

\author{
M.V. Bogdanovich ${ }^{\text {a }}$, G.I. Ryabtsev ${ }^{\text {a }}$, A.I. Yenzhyieuski ${ }^{a}$, L.I. Burov ${ }^{\text {b }}$, A.G. Ryabtsev ${ }^{\text {b }}$, M.A. Shchemelev ${ }^{b}$, \\ A.S. Smal ${ }^{\mathrm{c}}$ \\ ${ }^{\text {a }}$ B.I. Stepanovo Fizikos institutas, Minskas, Baltarusija \\ ${ }^{\mathrm{b}}$ Baltarusijos valstybinis universitetas, Minskas, Baltarusija \\ ${ }^{\mathrm{c}}$ Bresto valstybinis technikos universitetas, Brestas, Baltarusija
}

\section{Santrauka}

Išanalizuota rezonatoriuje pagautos sustiprintos liuminescencijos (RPSL) ittaka išilgai ir iš šonų diodais kaupinamų $\mathrm{Er}, \mathrm{Yb}$ : stiklo lazeriu generavimo slenksčiui, galiai ir dinaminėms charakteristikoms. Panaudojant liuminescencijos balanso lygtis, buvo įvertintas RPSL nuostolių koeficientas. Nustatyta, kad RPSL nuostoliu koeficientas atvirkščiai proporcingas rezonatoriaus ilgiui. Paro- dyta, kad luminescencijos stiprinimas rezonatoriuje žymiai padidina kaupinimo galios slenksti ( $\sim 3-5$ kartus). Buvo sumodeliuota $\mathrm{Er}, \mathrm{Yb}$ : stiklo lazerio generavimo dinamika, iskaitant liuminescencijos vystymąsi nuo diodinio kaupinimo impulso pradžios. Priklausomai nuo diodinio kaupinimo impulso amplitudès, galima pasiekti didesni ar mažesni Er, Yb : stiklo lazerio impulso generavimo vèlavimą. 